\title{
BLDC technology and its application in weapon system launching platform
}

\author{
Akhilesh K Mishra ${ }^{1 *}$, Mahesh K Roy ${ }^{2}$, V S Mohalkar ${ }^{3}$, and Rashmi Mishra ${ }^{4}$ \\ ${ }^{1}$ Scientist ' $E$ ',DRDO, R\&DE(Engineers), Dighi PO,Pune-411 015, INDIA \\ ${ }^{2}$ Scientist 'E',DRDO, R\&DE(Engineers), Dighi PO,Pune-411 015, INDIA \\ ${ }^{3}$ Scientist ' $C$ ', DRDO, R\&DE(Engineers), Dighi PO,Pune-411 015, INDIA \\ ${ }^{4}$ Project Trainee ,DRDO, R\&DE(Engineers), Dighi PO,Pune-411 015, INDIA \\ "Corresponding Author: e-mail: mishraakhilesh1@yahool.co.uk, Tel +91-20-27044604, Fax. +91-20-27044602.
}

\begin{abstract}
In this paper Brushless DC (BLDC) Technology and its Application in Articulation of Weapon System Launching Platform using Electromechanical Servo Drive is presented. The angular position or linear position of a system can be controlled by rotation or articulation in elevation and azimuth plane. In linear position control angular rotation of the BLDC motor is converted into linear motion by using Electromechanical Actuator to articulate in desired direction. For articulation of a weapon system launching platform, Electromechanical Servo Drives are used. Due to inherent properties of BLDC Technology BLDC Motors and Drives are profoundly used in military and strategic weapon system applications. In this paper, BLDC Motor and Electromechanical Servo Drive System, operating principle, modeling, characteristics and its application in various weapon system programs are discussed.
\end{abstract}

Keywords: BLDC Motor, Electromechanical Servo Drive, Positioning, Articulation, Weapon system launching platform.

DOI: http://dx.doi.org/10.4314/ijest.v4i1.2S

\section{Introduction}

Servo drives are used for position control of a system by controlling position, speed and acceleration. BLDC motors play very vital role in servo drives used in strategic defence applications. Brushless DC motors are being used in numerous applications as they offer advantages of DC motor and Induction motor both including reduced noise, long lifetime, reduced noise, good weight/size to power ratio, and hazardous operation environment usability. These types of motor have low rotor inertia in comparison to other motor types. A BLDC motor stator basically includes three coils, which can be replicated to reduce torque ripple. In the same way, a rotor basically includes permanent magnets, composed of one to multiple pair of poles; this also affects step size. Position of the rotor can be estimated using three hall sensors mounted on stator and spread at $120^{\circ}$ around the stator AMTEL. Three logic signals are decoded to determine the next winding sequence. A three-phase motor requires three push pull stages. In each of the six possible states, two outputs are active at a given time (current flows in only two windings of the stator). Each state translates to electrical sectors (lshnatek). In many strategic system applications a load is articulated from one position to other position in specified time to meet the mission requirement. Electromechanical servo drives are used in these applications due to its inbuilt qualities and advantages to rotate or move loads from one position to other (Kannan, 2010) in desired automated manner. In most of these applications BLDC motor is preferred over AC or DC motor as it exhibits the property of both AC and DC motors. In this paper, a discussion on BLDC technology and its application in Electromechanical Servo Drive used in weapon system launching platform is presented. BLDC motor is discussed in comparison with DC motor. Electromechanical Servo Drive system used in weapon system launching platform is discussed with control philosophy. BLDC motor modeling, equivalent circuit and simulation in MATLAB are also presented. 


\section{Brushless DC Technology}

Brushless DC Technology is primarily used in motors where the physical commutator is removed and current commutation is achieved through Electronics Switching of voltage in the suitable stator winding. In a DC motor the stator is a permanent magnet. The rotor has the windings, which are excited with a current. The current in the rotor is reversed to create a rotating or moving electric field by means of a split physical commutator and brushes. On the other hand, in a BLDC motor the windings are on the stator and the rotor is a permanent magnet as shown in Figure 2.1 (Sitapati, 2010). To make the rotor run, a rotating electric field is required. Typically a three-phase BLDC motor has three stator phases that are excited two at a time to create a rotating electric field. The excitation on the stator must be sequenced in a specific manner while knowing the exact position of the rotor magnets. This prevents the permanent magnet rotor from getting locked with the stator. Position information is obtain by either a shaft encoder or oftenly by Hall effect sensors that detect the rotor magnet position. For a typical three phase, sensored BLDC motor there are six distinct regions or sectors in which two specific windings are excited (Parlikar, 2011).

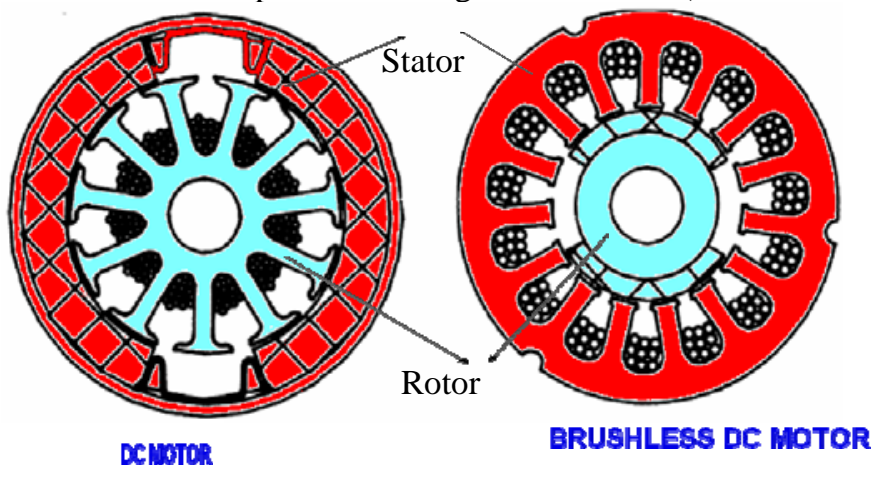

Figure 2.1: DC Motor and BLDC Motor

A 3-bit code is obtained with values ranging from 1 to 6 by reading the Hall effect sensors. The present rotor location is depicted by each code value. Each code value gives us information on which windings the current is needed to be injected. Thus a simple lookup table is used by the program to determine which two specific windings are to be excited and this runs the rotor in the manner as shown in Figure 2.2.

Thus physical commutator in DC motor is replaced by electronic commutation mechanism by sensing the rotor pole position by using three Hall effect sensors mounted on the stator. As shown in Figure below, two windings of stator are excited together for completing the circuit to allow the current to flow from source to generate suitable magnetic pole in stator and rotor air gap for developing suitable torque in the motor.

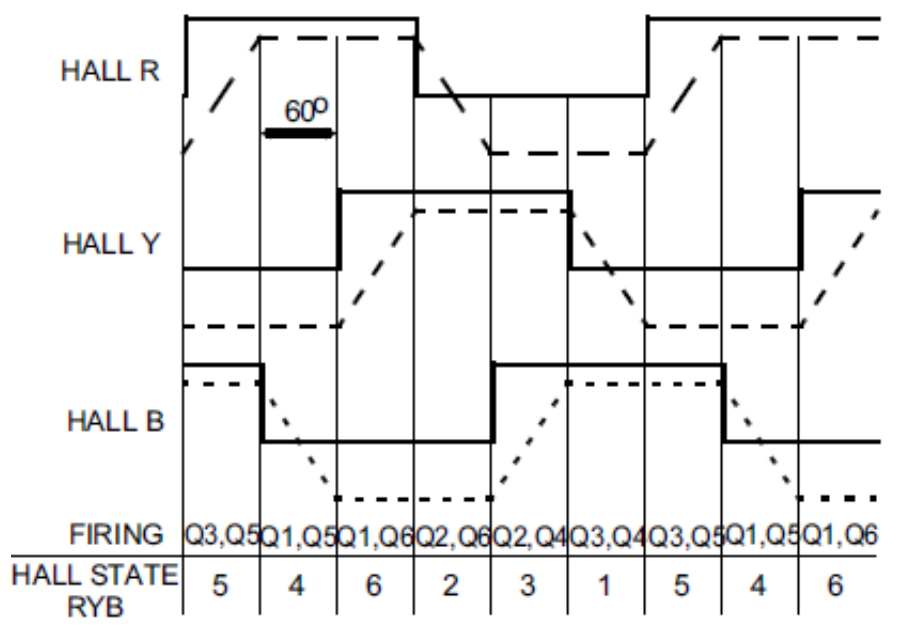

Figure 2.2: BLDC Commutation Diagram 


\section{Weapon System Launching Platform}

Weapon System Launching Platforms are used to carry, orient, hold and launch weapons in specified time with predefined profile as shown in Figure 3.1. This launcher gets signal from command centre and positions the platform in a predefined state suitable to fire the weapons accurately to engage the target at desired location. For this purpose the launching platform is rotated in azimuth and elevation axes simultaneously. To achieve this two Electromechanical Servo Drives are used, one to rotate the platform in Azimuth plane and other to rotate in Elevation plane. The design of the drives is carried out considering the following inputs:

(a) Torque requirement at the time of rotation

(b) Torque requirement at the time of holding

(c) Speed profile of the motor during rotation

(d) Time requirement of the mission

(e) Power requirement of the drive

(f) Protection requirement

(g) Transmission Mechanism i.e. gear type

(h) Gear to motor speed ratio

In below section an Electromechanical Servo Drive and its control is discussed in details.

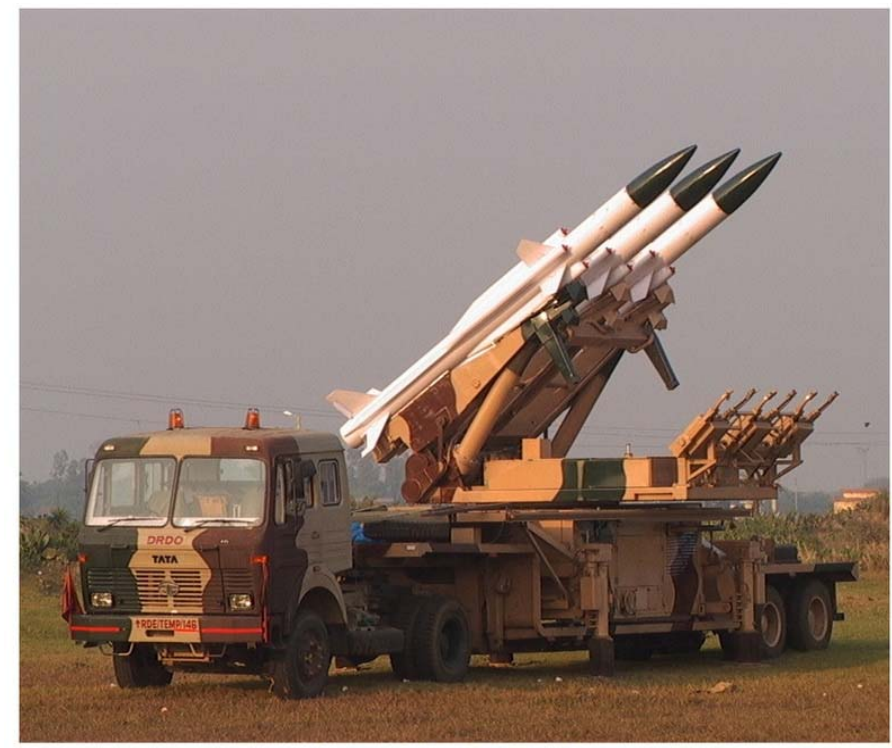

AKASH AIR FORCE LAUNCHER

Figure 3.1: Akash Missile Launching Platform on Wheeled Vehicle (downloaded from internet)

\section{Electromechanical Servo drive \& Control}

Electromechanical Servo Drives used in articulation of weapon system launching platform mainly consists of Electrical servo Drive and Mechanical Actuator along with launch beam as load. The functional requirement of the drive system is to orient the weapon system accurately in vertical plane in specified time. Electro-mechanical servo drive system is selected for accurate positioning \& fast response due to its increased reliability \& safety, better maintainability, silent operation in field and reduced overall cost.

Figure 4.1 shows photograph of the developed electromechanical servo drive. The main subsystems are:

1. Launch Beam,

2. BLDC Motor \& Drive,

3. Gear Box and

4. Screw actuator

The weight of launch beam along with its payload and the speed of articulation are basis of the design and selection of the other three subsystem of this Electromechanical Servo Drive. There must be suitable margin in the selection and design of these subsystems to meet the requirement of known reactions and unknown reactions.

This drive consists of pair of Ball screw actuators, differential gear box, EM fail safe brake, BLDC servomotor and sensors for velocity \& position feedback. The launch beam is pivoted at its one end and carries payload of the weapon systems. The unbalanced torque due to this elevation mass in addition to torque due to acceleration, wind and frictional has to be given by drive 
motor. The Screw actuators are driven by BLDC motor through differential gearbox. Electro-Magnetic brake is integrated between the gear box and drive motor in a failsafe configuration. The brake is s released only when the drive is powered. EM brake is used to hold the elevation axis stationary when drives power are off.

The control system of Electromechanical Servo Drive is based on PC or Electronic Controllers with various peripheral modules to interface with mechanical and electrical systems. The control system is required to operate the Elevation drive to move the launching platform to a final commanded position. Control system takes inputs from position and velocity sensors, fitted on appropriate locations, to achieve the desired positional accuracies within specified time limit. The commanded position to be achieved can be fed to controller from operator's panel provided with control system. The control algorithm continuously calculates the error between command and feedback and updates the output actuation accordingly.

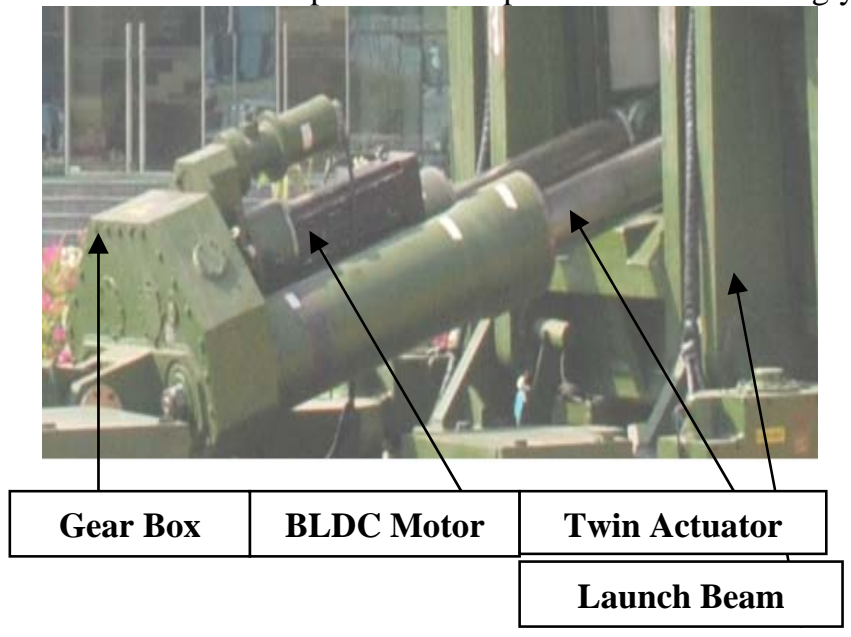

Figure 4.1: Electromechanical Servo Drive System

Suitable angular sensors are used for the position feedback for elevation axis and properly converted digital output of position sensor is compared with position reference entered on the local console. The position error is computed and fed to the power amplifiers through suitable digital to analog converter. These power amplifiers in turn control the position of elevation axis. Failsafe type electromagnetic brakes are provided on elevation axis which shall maintain the current position during power failures or when the position reference is steady. The Compatible amplifier cum motor drive module for BLDC motors have been considered for the Elevation. Readily developed and available military servo amplifier system modules based on IGBT devices are used for this project. These modules are fully digital so that they can easily be adapted to each application by means of user friendly program running on the conventional PC.

\section{Modeling of the BLDC motor and its Simulation}

The model of the BLDC motor is shown in Figure 5.1. This model is developed using the parameters of the motor used in the application as shown in Figure 4.1. In this model, the controlled signal obtained from servo amplifier is fed to the field winding. With the help of constant current source the armature current is maintained constant.

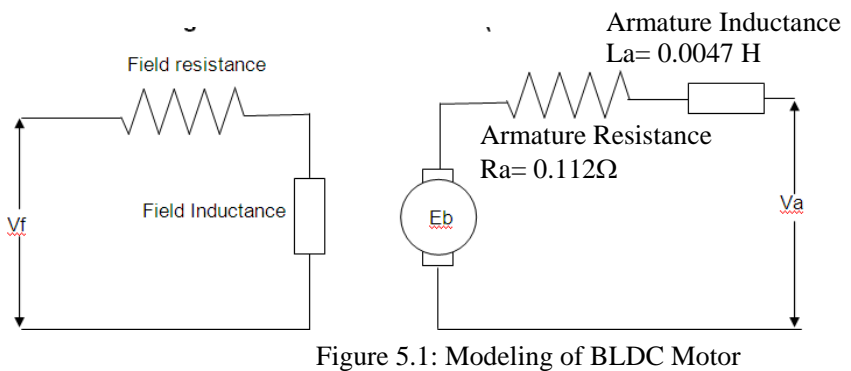

The following assumptions and equations are used to derive this model.

Motor torque $\mathrm{Tm}$ is proportional to product of flux and armature current

$$
\begin{aligned}
& \text { Tm } \alpha \varphi . I a \\
& T m=K t . I a
\end{aligned}
$$

Where, $\varphi$ is flux and $I a$ is armature current. 
Back Emf is directly proportional to shaft velocity $\varpi_{m}$

$$
E_{b}=K_{b} \varpi_{m}(s)
$$

Applying Kirchoff's law to armature circuit we get,

$$
e_{a}=E_{b}+I_{a}\left(R_{a}\right)+L_{a} \frac{d i_{a}}{d t}
$$

Using above equations block diagram of BLDC motor model is derived and is shown in Figure 5.2.

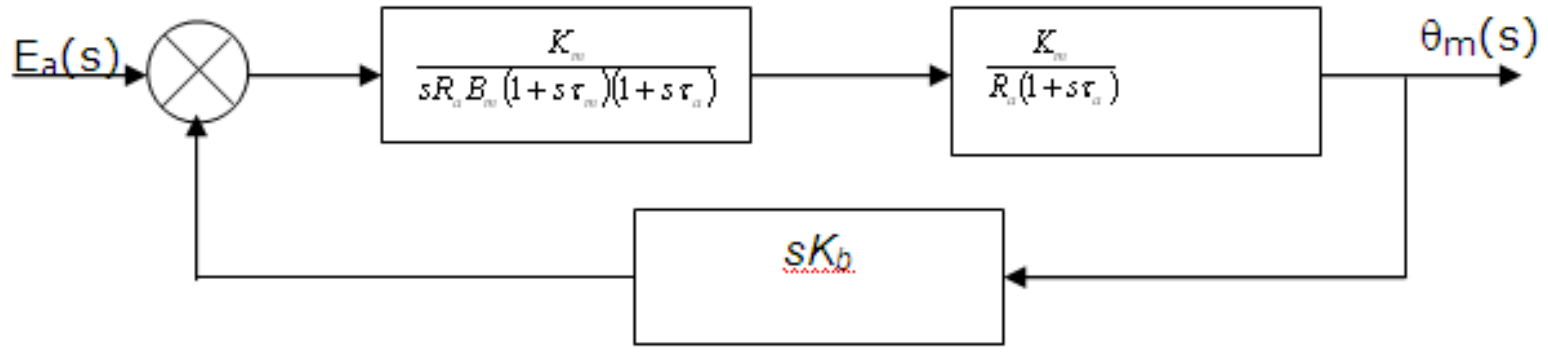

Figure 5.2: Block diagram of BLDC Motor model

Motor Parameters are as follows:

- Motor armature resistance $(\mathrm{Ra})=0.112 \Omega$

- Motor armature inductance $(\mathrm{La})=0.0047 \mathrm{H}$

- Motor armature inertia $(\mathrm{Jm})=0.0168 \mathrm{~kg}-\mathrm{m}^{2}$

- Motor Static friction $(\mathrm{Bm})=1.76 \mathrm{Nm}$

- Motor Viscous damping factor $=0.358 \mathrm{~N}-\mathrm{m} / \mathrm{krpm}$

- Back emf constant $(\mathrm{Kb})=0.142$

- Torque constant $(\mathrm{Kt})=2.35 \mathrm{~N}-\mathrm{m} / \mathrm{Amps}$

The response of BLDC motor model is shown in Figure 5.3.

\section{BODE PLOT}

STEP RESPONSE

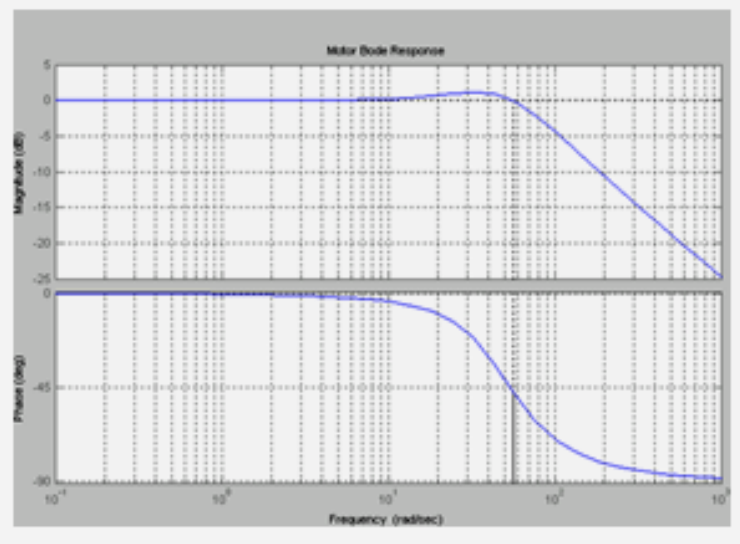

$\mathrm{G} \cdot \mathrm{M}=$

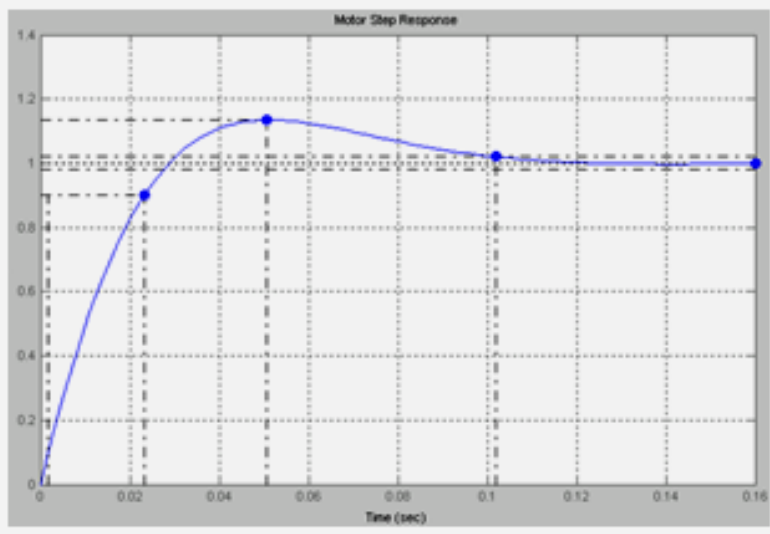

Figure 5.3: Response of the motor model

It is observed from the above that Settling Time $=0.102$ secs, $\mathrm{P} . \mathrm{M}=133^{\circ}$ at $56.8 \mathrm{rad} / \mathrm{sec}$. These values are within desired limit. The BLDC motor with sudden change in load torque is modelled using MATLAB and the model is shown in Figure 5.4. The motor parameters are used to simulate this model. The response of the model for armature current response, speed and torque at motor shaft captured and are shown in Figure 5.5. These responses meet the requirement of the system and are well within the desired limits. 


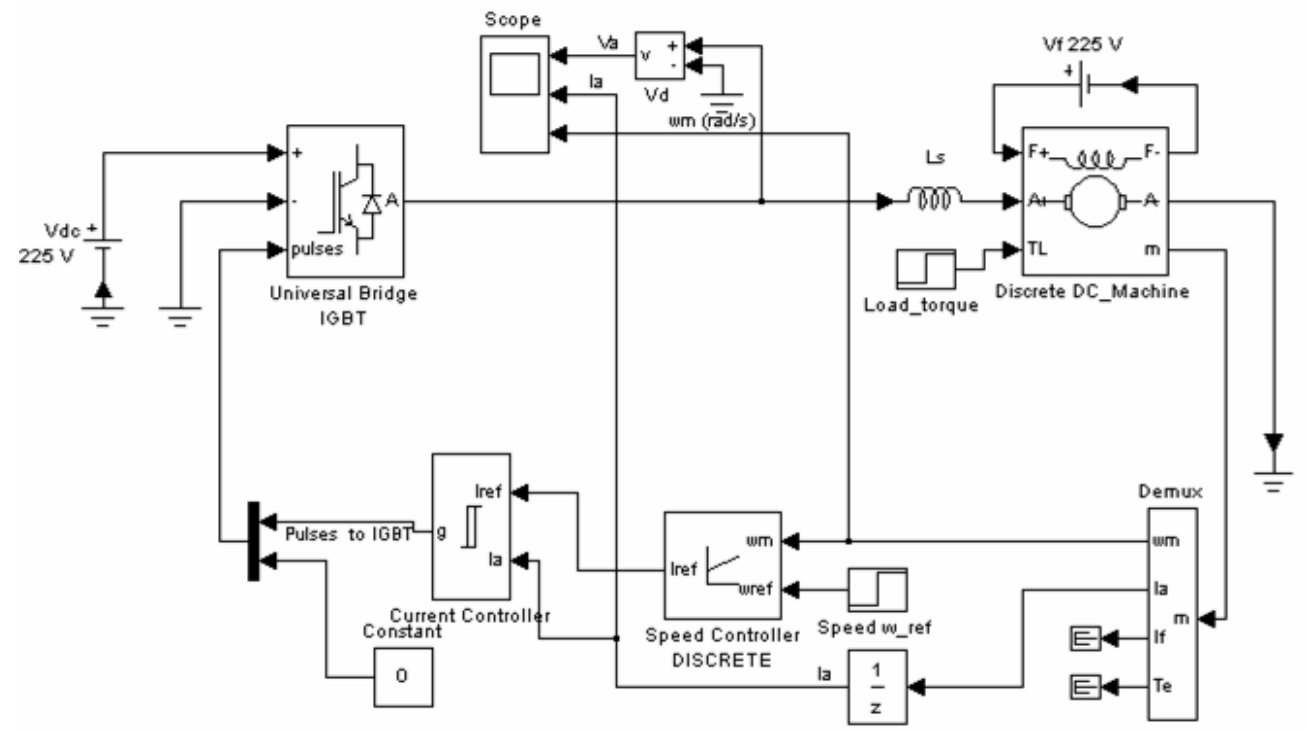

Figure 5.4: Modeling of Motor with sudden change in torque

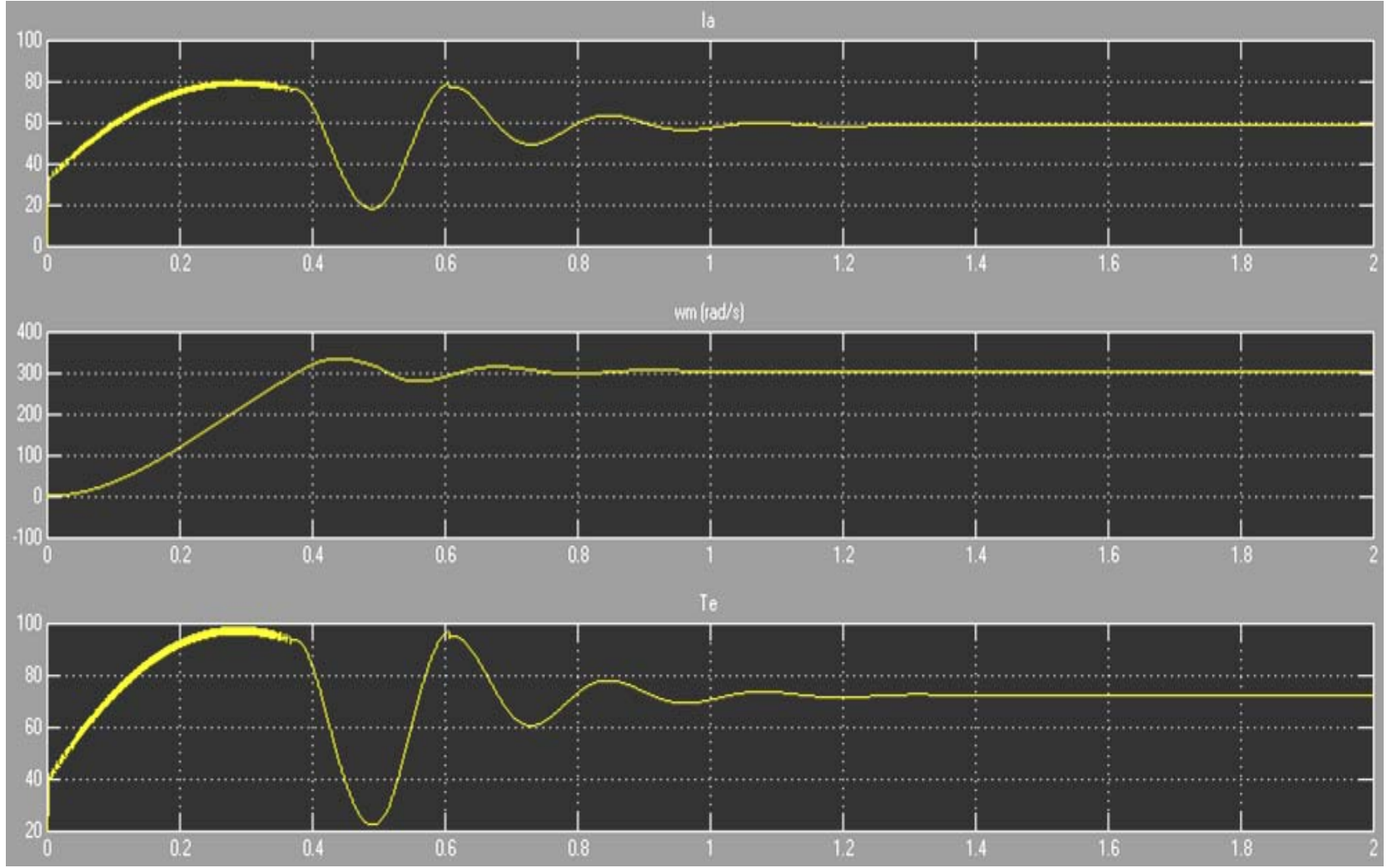

Figure 5.5: Response of the motor model with sudden change in torque

The speed-torque characteristics as shown in Figure 5.6 exhibits practically linear behavior at different voltages (D' Souza, 2004). It can be mathematically expressed as equation of a line i.e. $\mathrm{y}=\mathrm{mx}+\mathrm{c}$. So, it can be represented with just 2 points for a given voltage (No-load speed, Stall torque). Performance of BLDC motor can be estimated at any voltage with additional parameters. 


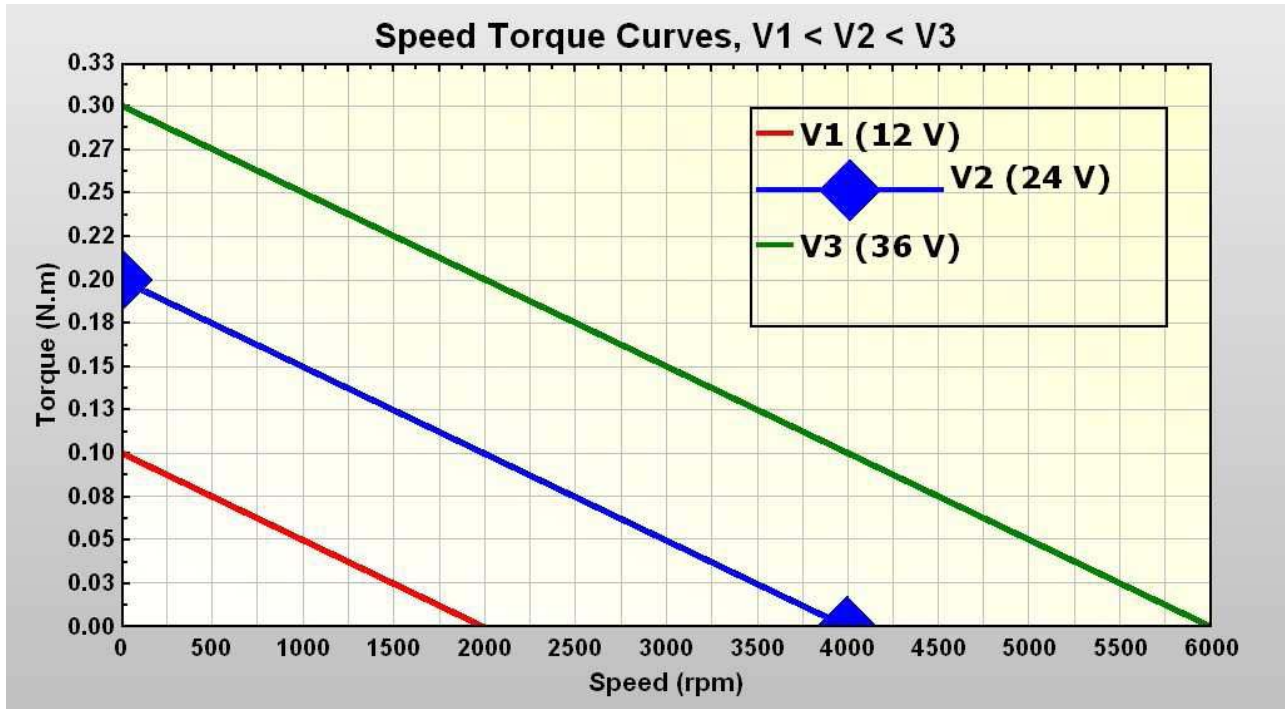

Figure 5.6: Speed-Torque Characteristics

\section{Conclusion}

In this paper, BLDC Motor and its application in Electromechanical servo drive system used in articulation of weapon system launching platform is presented. Comparative study of BLDC motor with DC motor is presented in section II. A weapon system launching platform is discussed in section III. The developed Electromechanical Servo Drive system using BLDC motor is shown in Figure 4.1. Electrical servo drive system and its control details are discussed in section IV. Modelling of BLDC motor and its equivalent circuit is discussed in section V. BLDC model is simulated in MATLAB and its Bode Plot and step response are shown. The simulated responses are found to be within specified limits. The motor is mathematically modelled and simulated to verify its response for sudden change in the input torque. Its speed-torque characteristic is also discussed. After design calculations and simulations the electromechanical servo drive system with BLDC Motors is successfully developed and implemented in one of the prestigious weapon system application.

\section{References}

ATMEL .Fully Integrated BLDC Motor Control. Application Note.,4987A-AUTO-03/07, D’Souza S.2004., Sensored BLDC Motor Control Using dSPIC30F2010. Documents No. DS00957A, Microchip Technology. Ishnatek Systems \& Services Pvt ltd. implementing a Brushless DC Motor Controller on an IGLOO FPGA. Application Note. Kannan N., 2010. The Brushless DC Motor for Aerospace Applications CEP Lecture Note at RCI Hyderabad on $03^{\text {rd }}$ November Parlikar V V,, Kurulkar P M, Mishra Akhilesh K, Kulkarni A N and Ganguly C. 2011., Electromechanical Servo Drive System for Articulation of Heavy Load Weapon System Launching Platform., National Conference on Advances and Research in Electrical System Technology (AREST’11), Arya Institute of Engg \& Technology Jaipur, 23-24 April

Sitapati K.. 2010., Brief Description of BLDC Motor Design and Simulation: Behind The Software. CEP Lecture Note, RCI Hyderabad on $03^{\text {rd }}$ November

\section{Biographical notes}

Dr A K Mishra received M.Tech and PhD from IT BHU Varanasi, India in 1992 and 2003 respectively. He is Scientist 'E' at R\&DE (Engrs), DRDO, Pune. He has more than 15 years of experience in teaching, research and development. His current fields of interest are the design and development of Electromechanical Servo Drive System for Weapon Launchers and Ground System Equipments for various strategic Weapons System Programmes being executed by DRDO. He is Life Member of Society of EMC Engineers (India) and Fellow Member of Institution of Engineers (India). He has published more than 15 papers in various conferences and journals.

M K Roy received B.Tech. from Devi Ahilya University, Indore, India in 1996. He is Scientist 'E’ at R\&DE (Engrs), DRDO, Pune. He has more than 15 years of experience in research and development. His current fields of research are the design and development of different Power Sources and Drives for different Launcher Platform with Ground System various strategic Weapons System Programmes undergoing at R\&DE(Engrs). 
V S Mohalkar received B.Tech. from Institution of Engineers (India), Calcutta, India in 1990. He is Scientist 'C' at R\&DE (Engrs), DRDO, Pune. He has more than 29 years of experience in research and development. His current fields of research are the design and development of different Launcher Platform with Ground System Equipments various strategic Weapons System Programmes being executed by DRDO.

Rashmi Mishra is pursuing her graduation degree in Instrumentation and Control Engineering at AISSMS IOIT, Pune, Maharashtra and likely to get her Bachelor of Engineering degree in Aug2012. She is pursuing her project work at Robotics Group of R\&DE(Engrs), DRDO, Pune as part of her degree course. Her area of interest is Power Electronics and sensors used in Robotics.

Received January 2012

Accepted February 2012

Final acceptance in revised form March 2012 